\title{
Thoracic endovascular aortic repair (TEVAR) in proximal (type A) aortic dissection: Ready for a broader application?
}

\author{
Christoph A. Nienaber, MD, PhD, ${ }^{\mathrm{a}, \mathrm{e}}$ Natzi Sakalihasan, MD, PhD, ${ }^{\mathrm{b}}$ Rachel E. Clough, MD, PhD, ${ }^{\mathrm{c}, \mathrm{f}}$ \\ Mohamed Aboukoura, MD, ${ }^{\mathrm{d}}$ Enrico Mancuso, MD, ${ }^{\mathrm{a}}$ James S. M. Yeh, MD, PhD, ${ }^{\mathrm{a}, \mathrm{e}}$ \\ Jean-Olivier Defraigne, MD, ${ }^{\mathrm{b}}$ Nick Cheshire, $\mathrm{MD}, \mathrm{PhD},{ }^{\mathrm{a}}$ Ulrich Peter Rosendahl, $\mathrm{MD}$, \\ Cesare Quarto, MD, and John Pepper, MD, $\mathrm{PhD}^{\mathrm{a}}$
}

\begin{abstract}
Objective: Thoracic endovascular aortic repair (TEVAR) has demonstrated encouraging results and is gaining increasing acceptance as a treatment option for aortic aneurysms and dissections. Yet, its role in managing proximal aortic pathologies is unknown - this is important because in proximal (Stanford type A) aortic dissections, $10 \%$ to $30 \%$ are not accepted for surgery and $30 \%$ to $50 \%$ are technically amenable for TEVAR. We describe our case series of type A aortic dissections treated by using TEVAR.
\end{abstract}

Methods: Between year 2009 and 2016, 12 patients with acute, subacute, or chronic type A aortic dissection with the proximal entry tear located between the coronaries and brachiocephalic artery were treated with TEVAR at 3 centers. Various stent-graft configurations were used to seal the proximal entry tear in the ascending aorta under rapid pacing.

Results: A total of 12 patients ( 9 male, 3 female), mean age $81 \pm 7$ years, EuroSCORE II $9.1 \pm 4.5$, underwent TEVAR for the treatment of type A aortic dissection. Procedural success was achieved in 11 of 12 patients $(91.7 \%)$. There was 1 minor stroke and 1 intraprocedural death. No additional deaths were reported at 30 days. At 36 months, there were 4 further deaths (all from nonaortic causes). The mean survival of these 4 deceased was 23 months (range 15-36 months). Follow-up computed tomography demonstrated favorable aortic remodeling.

Conclusions: TEVAR is feasible and reveals promising early results in selected patients with type A aortic dissection who are poor candidates for surgical repair. The current iteration of stent-graft technology, however, needs to be adapted to features specific to the ascending aorta. (J Thorac Cardiovasc Surg 2017;153:S3-11)

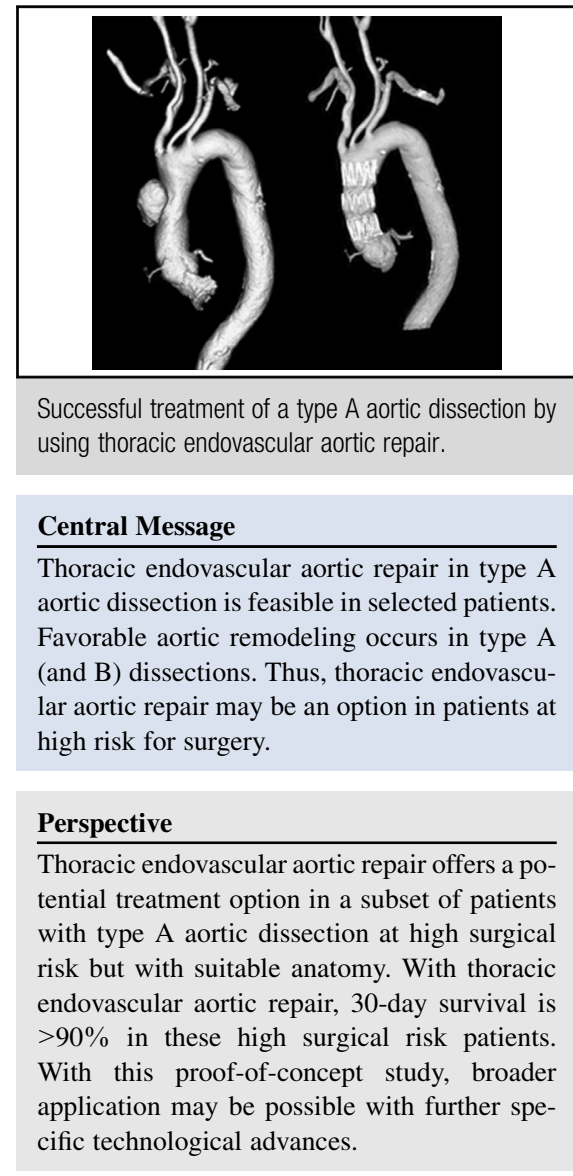

See Editorial Commentary page S12.

\footnotetext{
From the ${ }^{\mathrm{a}}$ Royal Brompton Hospital, London, United Kingdom; ${ }^{\mathrm{b}}$ Université Catholique de Liège, Liège, Belgium; ${ }^{\mathrm{c}}$ Aortic Centre, Hôpital Cardiologique, CHRU Lille, Lille, France; ${ }^{\mathrm{d} D e p a r t m e n t}$ of Cardiology, University Hospital Rostock, Rostock, Germany; ${ }^{\mathrm{e}}$ National Heart and Lung Institute, Imperial College London, London, United Kingdom; and ${ }^{\mathrm{f}}$ Division of Imaging Sciences and Biomedical Engineering, King's College London, London, United Kingdom.

Read at the 2016 Annual Aortic Symposium of the American Association of Thoracic Surgeons, New York, New York, May 12-13, 2016.

Received for publication May 17, 2016; revisions received July 6, 2016; accepted for publication July 30, 2016; available ahead of print Sept 28, 2016.

Address for reprints: Christoph A. Nienaber, MD, PhD, Cardiology and Aortic Centre Royal Brompton Hospital, Royal Brompton and Harefield NHS Foundation Trust, Sydney St, London SW3 6NP, United Kingdom (E-mail: c.nienaber@ rbht.nhs.uk). $0022-5223 / \$ 36.00$

Copyright (c) 2016 by The American Association for Thoracic Surgery

http://dx.doi.org/10.1016/j.jtcvs.2016.07.078
}

Surgical mortality and morbidity remain high for proximal (Stanford type A) aortic dissections, particularly in elderly patients with significant comorbidities, despite recent strides to improve its surgical technique and

Scanning this QR code will take you to the videos for the article.

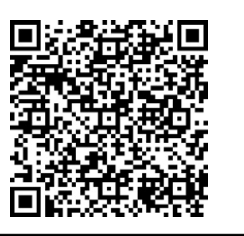




\section{Abbreviations and Acronyms}

$\mathrm{CT}=$ computed tomography

$\mathrm{SD}=$ standard deviation

TEVAR $=$ thoracic endovascular aortic repair

management. ${ }^{1,2}$ Considering the Western demographics with increasing aging population and variety of comorbidities that portend inherent increased surgical risks, the concept of endovascular stent-grafting, also known as thoracic endovascular aortic repair (TEVAR, a catheter-based nonsurgical technique), in patients with thoracic aortic disease is increasingly attractive, propelled by the desire to minimize surgical risks. TEVAR has been shown to initiate healing and remodeling of the dissected aorta by excluding and depressurizing the false lumen. ${ }^{3-5}$ To date, TEVAR strategies appear encouraging in the treatment of various aortic pathologies. ${ }^{6-10}$ The technology has been embraced without level I evidence for the treatment of distal (Stanford type B) aortic dissections and even used to treat acute proximal (Stanford type A) aortic dissections ${ }^{11}$; however, the complexity of the anatomy in the ascending aorta continues to be a major obstacle for the use of endovascular technologies.

Acute type A aortic dissection usually requires very urgent surgical repair of the ascending aorta ${ }^{12-14}$; selected cases, however, may qualify for TEVAR as an option in scenarios of unacceptably high surgical risk. According to the International Registry of Acute Aortic Dissections, $86 \%$ patients qualify for surgical replacement of the ascending aorta, and $23 \%$ or $12 \%$ require additional partial or total arch replacement, respectively. ${ }^{15}$ Overall, in aggregate $91 \%$ of patients in this registry underwent surgical repair under cardiopulmonary bypass with $25 \%$ in-hospital mortality. ${ }^{15,16}$ A less-traumatic repair of type A aortic dissection by using TEVAR, where applicable, may potentially lower the procedural/in-hospital mortality risk, particularly as the technology improves.

Surgical repair leaves a patent false lumen in both the aortic arch and descending aorta in $75 \%$ of patients; those who survive often require distal reintervention(s)..$^{15,16}$ One solution may be a 2-stage hybrid procedure, whereby initially surgery is performed to replace the ascending aorta together with aortobrachiocephalic artery bypass without hypothermic circulatory arrest. This is followed on a second occasion by surgery for left carotid artery bypass and TEVAR to retrogradely place an endovascular stent-graft in the thoracic aorta transfemorally in the same setting. The stent-graft excludes the retrogradely perfused distal false lumen. ${ }^{17}$ The objective of such an approach is to avoid surgery on the arch and to complete the repair with an aortic stent-graft in a minimally invasive way. Such an approach not only minimizes the procedural risks but also enables careful evaluation of the distal false lumen before stentgraft placement. Alternatively, 1-stage hybrid procedures combining open (surgical) insertion of an tube-graft in the ascending aorta with head vessel transposition and antegradely placing an endovascular stent-graft in the arch and descending aorta are feasible ${ }^{18}$ but require the skills of both a cardiac and endovascular specialist and lack the precision of the 2-stage hybrid procedure. ${ }^{19}$ Moreover, there is some resistance to apply such 1-stage hybrid procedures in acute type A aortic dissections, because experts are aware that the fragile outer aortic wall and friable dissecting lamella are prone to injury or perforation by antegrade positioning of the stent-graft under conditions of circulatory arrest. At present, there are no dedicated stent-grafts for the ascending aorta, in particular for the repair of aortic dissections; such challenges will certainly be addressed by customized stent-graft technology in the near future. Nevertheless, the concept of a 1-stage hybrid repair with antegrade stent-graft placement may become part of a therapeutic armamentarium for complex type A dissections with distal malperfusion; while a multistage hybrid repair incorporating retrograde stentgraft placement may become a preferred option in stable situations.

From an anatomical perspective, $30 \%$ to $50 \%$ patients with type A aortic dissection are amenable to TEVAR. ${ }^{20,21}$ Thus, in the future more patients may be considered suitable for TEVAR with life-long follow-up. The ultimate goal is a fully catheter-based approach to repair the ascending aorta that minimizes procedural risk and initiates healing (as documented in type B dissections in which interventional entry closure is associated with thrombosis of the false lumen and favorable aortic remodeling). ${ }^{3,4,6,7}$ Such approach is feasible with current technology. ${ }^{22-25}$ Here, we describe our 12-case series of type A aortic dissections treated using TEVAR.

\section{METHODS \\ Patient Selection}

Between year 2009 and 2016, 12 patients with type A aortic dissection consisting of an isolated dissection entry in the ascending aorta, referred to the University Hospital Rostock (Rostock, Germany), CHU (Liege, Belgium), and Royal Brompton Hospital (London, United Kingdom) were selected and subjected to TEVAR. These patients were selected for TEVAR because of high comorbidities and anatomic suitability, for instance, aortic dimensions suitable to accommodate a ready-made commercial stent-graft. All had elevated anesthetic risk score (American Society of Anesthesiologists classification IV or greater), New York Heart Association class III or IV, chronic lung disease, and/or renal impairment. Decisions regarding treatment required consensus between cardiac surgeons and cardiologists, with the patients providing informed written consent. TEVAR in this setting was approved by the internal review board of each center. All patients had electrocardiogram-gated computed tomography (CT) (Figure 1) and echocardiography for the diagnosis and assessment of aortic dissection. Echocardiography allowed assessment of 
the aortic valve, left ventricular function, presence/absence of tamponade, and interrogation of the supra-aortic vessels.

\section{TEVAR Procedure}

Procedural planning was based on contrast-enhanced, electrocardiogram-gated CT (Figure 1), which was evaluated with standard software (TeraRecon [Foster City, Calif] or 3Mensio [PIE Medical Imaging, Maastricht, The Netherlands]) to select the appropriate stent-graft size; the diameter of the stent-graft was chosen according to an estimate of the previous (before dissection) aortic dimension to avoid oversizing. The stent-grafts used were usually ZENITH TX2 (Cook, Bloomington, Ind), GORE C-Tag (Gore Ltd, London, United Kingdom), or Relay NBS (Bolton, Barcelona, Spain). They are made of a self-expanding nitinol stent platform covered with polyester fabric. They are packed and mounted onto a catheter-based delivery system.

Figure 2 and Videos 1-3 show a typical TEVAR procedure. With the patient under general anesthesia, a temporary pacing wire was placed in the right ventricle and vascular access for the TEVAR device (22-24 F) obtained via femoral arterial cut-down. The true lumen of the aorto-ilio-femoral arterial route was navigated using a soft long hydrophilic guide wire (Terumo Medical Corp, Somerset, NJ) protruding ahead of a pigtail catheter to reach the left ventricle under fluoroscopy and ultrasound guidance (transesophageal echocardiography) ${ }^{26}$ Once the pigtail is in the left ventricle, the soft hydrophilic guide wire was exchanged to a stiff $270 \mathrm{~cm}$ length guide wire through the pigtail catheter. The stiff guide wire has a soft coiled tip that sits within the left ventricular cavity. The stent-graft was then delivered along the stiff guide wire to its intended position, where its distal landing zone is between distal to the coronary ostia and proximal to the brachiocephalic artery in the ascending aorta. In this position, the distal tip of the delivery system may cross the aortic valve. For stent-graft deployment, rapid right ventricular pacing at 180 bpm was used to reduce the systolic blood pressure to $\leq 50 \mathrm{~mm} \mathrm{Hg}$ to avoid displacement (windsock effect) of the stent-graft during its deployment, thus enabling its precise placement. At the end of the procedure, the temporary pacing wire was removed, the femoral artery access site closed, and the patient extubated and transferred to the coronary care unit. Procedural success was defined as successful placement of the stent-graft in its intended position with sealing of the entry tear.

\section{Follow-up}

Overall aortic and true lumen diameters were assessed at the level of sinotubular junction, ostium of the brachiocephalic artery, and left subclavian artery. Follow-up CT scans were performed approximately at 6 months and then annually post-TEVAR.

\section{Statistical Analysis}

Descriptive statistic was used to characterize patients, procedural data and individual survival.

\section{RESULTS}

A total of 12 patients with proximal (type A) aortic dissection were selected for TEVAR (Table 1). There were 10 DeBakey type II and 2 DeBakey type I dissections. The mean age \pm standard deviation (SD) was $81 \pm 7$ years; male/female ratio was 9:3. All patients were of advanced age with chronic lung disease, coronary artery disease, and/or renal impairment. The mean EuroSCORE II was $9.1 \pm 4.5$ (SD). The median time from onset of symptoms/diagnosis to TEVAR was 24 days. There were 6 cases of acute ( $\leq 14$ days after symptom onset) and 6 cases of subacute (15 days to 3 months) or chronic ( $>3$ months)
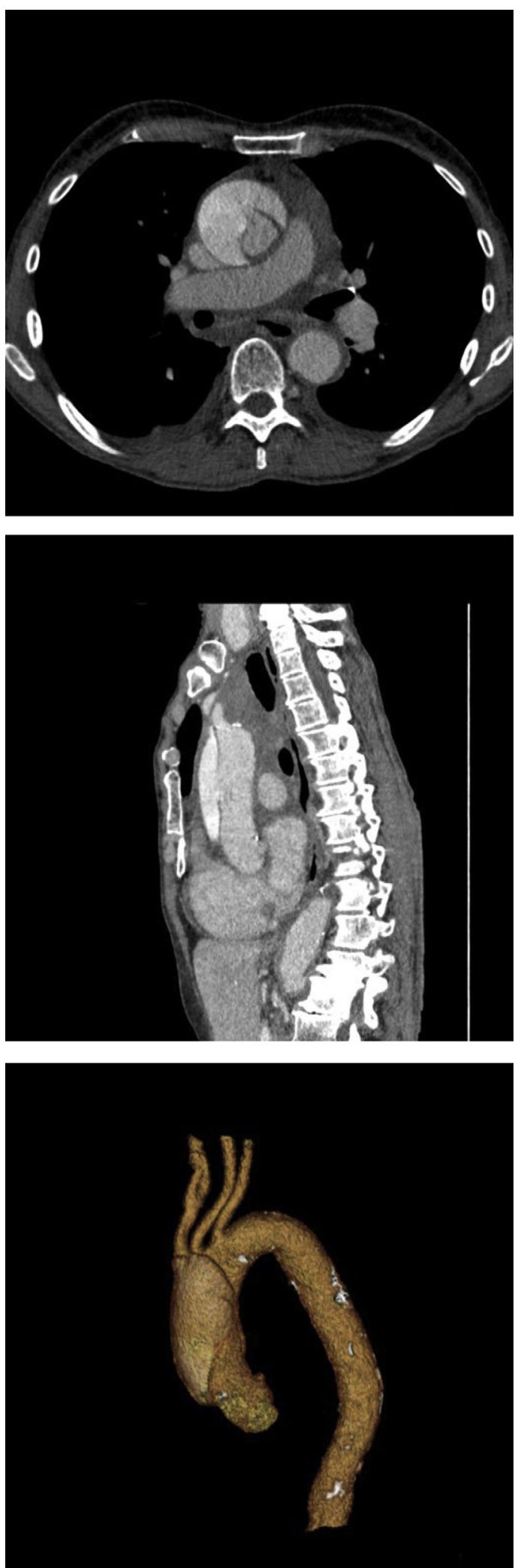

FIGURE 1. From top to bottom: 2-dimensional transverse and coronal section of a localized proximal aortic dissection (type A) with a large entry between the aortic valve and brachiocephalic artery; 3-dimensional reconstruction prior to treatment. 


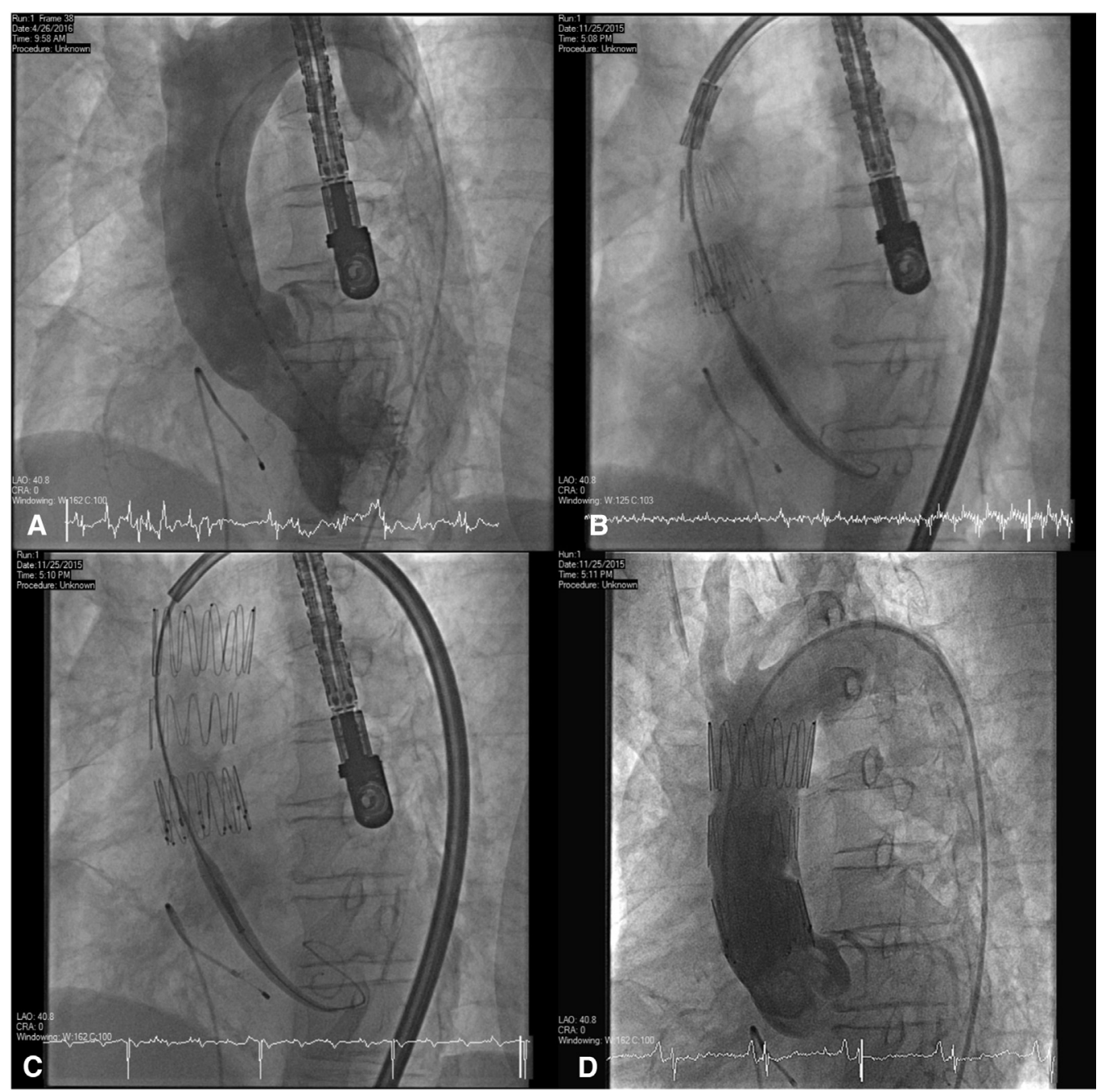

FIGURE 2. TEVAR procedural sequence for placing a covered stent-graft to treat a type A aortic dissection. A, Aortogram and set-up showing a right ventricular pacing wire and transesophageal echo probe. B, Stent-graft deployment during rapid pacing. C, Completed deployment of the stent-graft. $\mathrm{D}$, Aortogram demonstrating procedural success.

aortic dissections. The false lumen of the dissection expanded significantly causing various complications, including dyspnea, hoarseness, or laryngeal nerve dysfunction. There was a history of chest and back pain in all cases. There were no significant aortic insufficiency, no clinically apparent distal malperfusion syndromes and no distal interventions required.

Procedural success was $91.7 \%$ (11/12) (Table 1). There was 1 death attributable to cardiac tamponade from wire-induced perforation of the left ventricle. All remaining 11 patients were discharged alive within 2 weeks of TEVAR. The mean procedural time was $86 \pm 33$ (SD) minutes. Stent-grafts were deployed under rapid right ventricular pacing, which achieved a mean systolic pressure of $34 \pm 15(\mathrm{SD}) \mathrm{mm} \mathrm{Hg}$. The mean follow-up time was $21.1 \pm 11.8$ (SD) months (range 0-36 months) post-TEVAR. There were 4 deaths, one each at 15, 19, 23, and 36 months (Table 1). All appeared to have died from natural causes. The mean survival in those who died during follow-up was 23 months.

Follow-up CT scans revealed thrombosis or remodeling of the stent-graft excluded false lumen. The diameter of the aorta at the sinotubular junction was not enlarged and remained similar to the normal aorta post-TEVAR (Figure 3).

\section{DISCUSSION}

There is general consensus that proximal aortic dissection or any major pathology involving the ascending aorta should be subjected to surgical repair; however, $10 \%$ to $30 \%$ of patients with acute type A aortic dissection are considered too high risk for surgical repair and would therefore receive only medical therapy with associated high mortality of $\approx 60 \%$ in the intermediate 


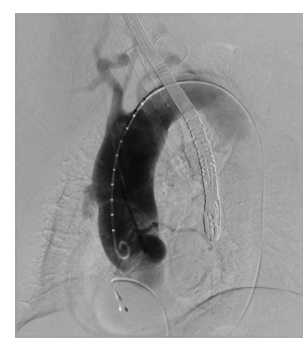

VIDEO 1. Before thoracic endovascular aortic repair. Digital subtraction angiogram showing a large tear in the ascending aorta and a marker pigtail, pacing wire, and transoesophageal echocardiography probe in place. Video available at: http://www.jtcvsonline.org/article/S0022-5223(16) 31049-2/addons.

term. ${ }^{13,15,27,28}$ Surgical mortality is $10 \%$ to $25 \%{ }^{16,27}$ depending on the complexity of the operation and the clinical status of the patient. In our hands, the procedural mortality of TEVAR was $8 \%$, which compares favorably with the published early endovascular mortality of $11 \%{ }^{18,19}$ Interestingly, the most anticipated complications such as major stroke did not occur. One minor stroke (transient) and one death from guide wire perforation of the left ventricle leading to fatal tamponade occurred.

We estimate the number of TEVAR procedures performed in this study relative to all emergency surgeries for type A aortic dissection in our 3 centers to be $\approx 2 \%$, or $6 \%$ to $17 \%$ of inoperable type A cases (assuming the incidence of type $\mathrm{A}$ dissection $\approx 40$ cases/year for a typical aortic center; therefore across 3 centers spanning the study period of 6 years, the total number of cases $=40$ cases $\times 6$ years $\times 3$ centers $=720$ cases; generally $10 \%$ to $30 \%$ of type A dissections are inoperable ${ }^{15}$ ).

Successful sealing of the false lumen entry with no development of proximal type I endoleak were achieved. During follow-up, no cases of endoleak were identified

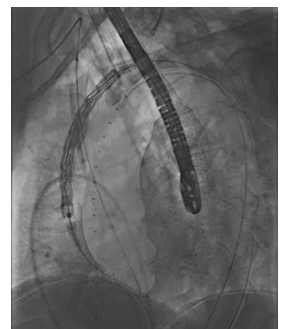

VIDEO 2. During thoracic endovascular aortic repair. Fluoroscopic display of the launch of a self-expanding Viabahn stent-graft in the brachiocephalic artery followed by a self-expanding C-Tag stent-graft covering the ascending aorta under rapid pacing. Video available at: http://www.jtcvsonline.org/article/S0022-5223(16)31049-2/addons.

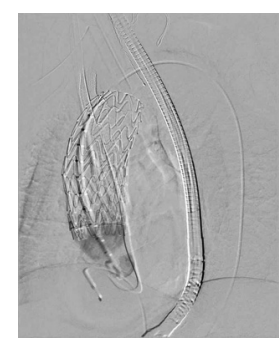

VIDEO 3. After thoracic endovascular aortic repair. Completion angiogram after placement of the Viabahn stent-graft in the brachiocephalic artery and C-Tag stent-graft in the ascending aorta; the entry to the dissection is sealed and flow is preserved to the brachiocephalic and coronary arteries. Video available at: http://www.jtcvsonline.org/ article/S0022-5223(16)31049-2/addons.

which is encouraging and different to $\approx 10 \%$ incidence reported elsewhere. ${ }^{29}$ In selecting the appropriate size of stent-grafts, we chose the diameter of the stent-grafts according to an estimate of the previous (before dissection) aortic dimension to avoid oversizing. The goal was to reshape the dissected ascending aorta, cover the entry tear, and depressurize the false lumen ${ }^{30,31}$; there is a fine balance between fixation to the aortic wall and the degree of intimal injury caused by the self-expanding stent-graft. Once precisely deployed, however, the process of remodeling of the false lumen appears similar between the proximal and distal dissection and takes place usually within 1 year, similar to that reported elsewhere. ${ }^{32,33}$ Most of our cases were DeBakey type II dissections, and even in the 2 cases of type I dissection (patients 2 and 3 in Table 1), favorable aortic remodeling of the descending aorta were observed. It seems that the therapeutic concept of closing the entry and depressurizing the false lumen in type B (distal) aortic dissection holds true also in type A (ascending) aortic dissection. ${ }^{3,4}$ As long as the false lumen is thrombosed and depressurized, survival even with type A aortic dissection can be improved by TEVAR. ${ }^{34}$ In addition, the patients' exposure to unacceptable risk of surgery is minimized.

Current literature (mostly single or small case series) underlines the feasibility of proximal endovascular procedures over more than 10 years, performed by surgeons and interventionalists (Table 2). ${ }^{22-25,30,31,33}$ Our series over 6 years with a mean follow-up of $>20$ months (range up to 3 years) underlines the fact that in the setting of significant comorbidities representing high surgical risk but with suitable anatomy, TEVAR can be a viable alternative to surgical repair. In other words, it is feasible to avoid high-risk/complex surgery and apply a lesstraumatic intervention to obtain a similar or better shortterm outcome in a subset of elderly patients with significant comorbidities. The advantages of TEVAR includes the avoidance of thoracotomy, cardiopulmonary bypass, 
TABLE 1. Patient details

\begin{tabular}{|c|c|c|c|c|c|c|c|c|}
\hline Patient & $\begin{array}{c}\text { Age }(y), \\
\text { sex }\end{array}$ & Diagnosis & EuroSCORE II & SG & $\begin{array}{c}\text { SG size } \\
\mathbf{D} \times \mathbf{L} \\
(\mathbf{m m})\end{array}$ & $\begin{array}{c}\text { Procedure } \\
\text { duration } \\
(\mathrm{min}) \\
\end{array}$ & $\begin{array}{c}\text { Procedural } \\
\text { complications }\end{array}$ & $\begin{array}{c}\text { Follow-up } \\
(\mathbf{m o})\end{array}$ \\
\hline 1 & $74 \mathrm{M}$ & cTAAD (DeBakey II) & 6.9 & Cook & $34 \times 77$ & 90 & None & 32 \\
\hline 2 & $75 \mathrm{M}$ & aTAAD (DeBakey I) & 8.1 & $\begin{array}{l}\text { Bolton } \\
\text { NBS }\end{array}$ & $34 \times 60$ & 140 & None & 29 \\
\hline 3 & $87 \mathrm{M}$ & aTAAD (DeBakey I) & 13.4 & $\begin{array}{l}\text { Bolton } \\
\text { NBS }\end{array}$ & $34 \times 60$ & 79 & None & 35 \\
\hline 4 & $89 \mathrm{M}$ & cTAAD (DeBakey II) & 15.0 & Cook & $36 \times 77$ & 149 & None & $15^{*}$ \\
\hline 5 & $90 \mathrm{M}$ & cTAAD (DeBakey II) & 19.3 & Cook & $36 \times 77$ & 70 & $\begin{array}{l}\text { Ventricular } \\
\text { rupture, } \\
\text { tamponade }\end{array}$ & $0 *$ \\
\hline 6 & $69 \mathrm{M}$ & aTAAD (DeBakey II) & 3.9 & Cook & $34 \times 77$ & 61 & None & $36^{*}$ \\
\hline 7 & $75 \mathrm{M}$ & cTAAD (DeBakey II) & 4.9 & $\begin{array}{l}\text { Bolton } \\
\text { NBS }\end{array}$ & $34 \times 60$ & 70 & None & 24 \\
\hline 8 & $87 \mathrm{M}$ & cTAAD (DeBakey II) & 9.4 & Cook & $36 \times 77$ & 49 & $\begin{array}{l}\text { Minor } \\
\text { Stroke }\end{array}$ & 15 \\
\hline 9 & $87 \mathrm{~F}$ & $\begin{array}{l}\text { aTAAD (DeBakey II, } \\
\text { post-TAVR) }\end{array}$ & 7 & Optimed & $32 \times 50$ & 120 & None & $23 *$ \\
\hline 10 & $83 \mathrm{M}$ & cTAAD (DeBakey II) & 6.9 & Cook & $34 \times 77$ & 89 & None & $19 *$ \\
\hline 11 & $75 \mathrm{~F}$ & aTAAD (DeBakey II) & 5.9 & Cook & $34 \times 77$ & 60 & None & 5 \\
\hline 12 & $75 \mathrm{~F}$ & aTAAD (DeBakey II) & 8.9 & $\begin{array}{l}\text { Gore }+ \text { Viabahn in } \\
\text { innominate artery }\end{array}$ & $34 \times 100$ & 60 & None & 0 \\
\hline
\end{tabular}

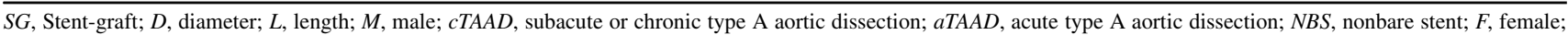
$T A V R$, transcatheter aortic valve replacement. *Deceased.

selective head perfusion, and associated surgical risks in an elderly population, often in a critical condition. ${ }^{35}$ If the high initial $\approx 60 \%$ mortality of type A aortic dissection can be successfully lowered by TEVAR, such less traumatic strategy may potentially become an option in a broader spectrum of patients. ${ }^{27}$ As TEVAR is a fairly expensive procedure, its associated lower risks/complications and shorter lengths of hospital stay compared with surgery may potentially demonstrate its advantages in terms of cost and clinical outcome over surgery.

TEVAR will not be feasible in every patient; the most suitable anatomy is where the entry tear of the dissection is located in the middle portion of the ascending aorta. Entry tears close to the coronaries or aortic valve lack a suitable length of landing zone. Entry tears close to the brachiocephalic artery would require complex branching/fenestration strategies. Currently, only a limited number of choices are available regarding the type of stent-graft and delivery system because relatively large diameter and short length stent-grafts are required. Existing delivery systems need to be modified for ascending aorta intervention: a long nosecone can either damage the aortic valve or increase the chance of left ventricular perforation by the stiff guide wire, as occurred in one of our patients.

On a technical note, with the use of rapid ventricular pacing no misplacement of these short stent-grafts was seen. Pacing is probably the most efficient method to avoid windsock effect of the left ventricle, enabling precise stent-graft placement. Transoesophageal echocardiography is also useful in guiding stent-graft positioning and assessing sealing of the entry tear. ${ }^{26}$

It should be emphasized that a multidisciplinary team, consisting of cardiac and vascular surgeons and cardiologists, should select suitable patients for the procedure, similar to transcatheter aortic valve replacement. Looking forward, we believe TEVAR in the ascending aorta is a definitive solution for patients not accepted for surgery, or a bridging solution in case of unclear neurological diagnosis (eg, major stroke) to buy time for reconstructive surgery. The selection process in patients not suitable for surgical valve replacement may even be conceivable for combined transcatheter aortic valve replacement-TEVAR technology, in an attempt to treat variants of aortic dissection including those with compromised aortic valve function. It also should be emphasized that in the acute setting there is a need to identify and transfer type A aortic dissection patients to a specialized unit as quickly as possible; once the dissection has produced coronary obstruction (usually the right coronary artery) with ensuing (right) ventricular infarction and heart failure, it is a difficult situation to retrieve by any intervention.

\section{Study Limitations}

Although we could demonstrate proof of concept and feasibility of TEVAR in the ascending aorta with encouraging results, we did not examine possible detrimental effects such as stiffening of the ascending aorta by the stent, lowered vascular compliance, negative 

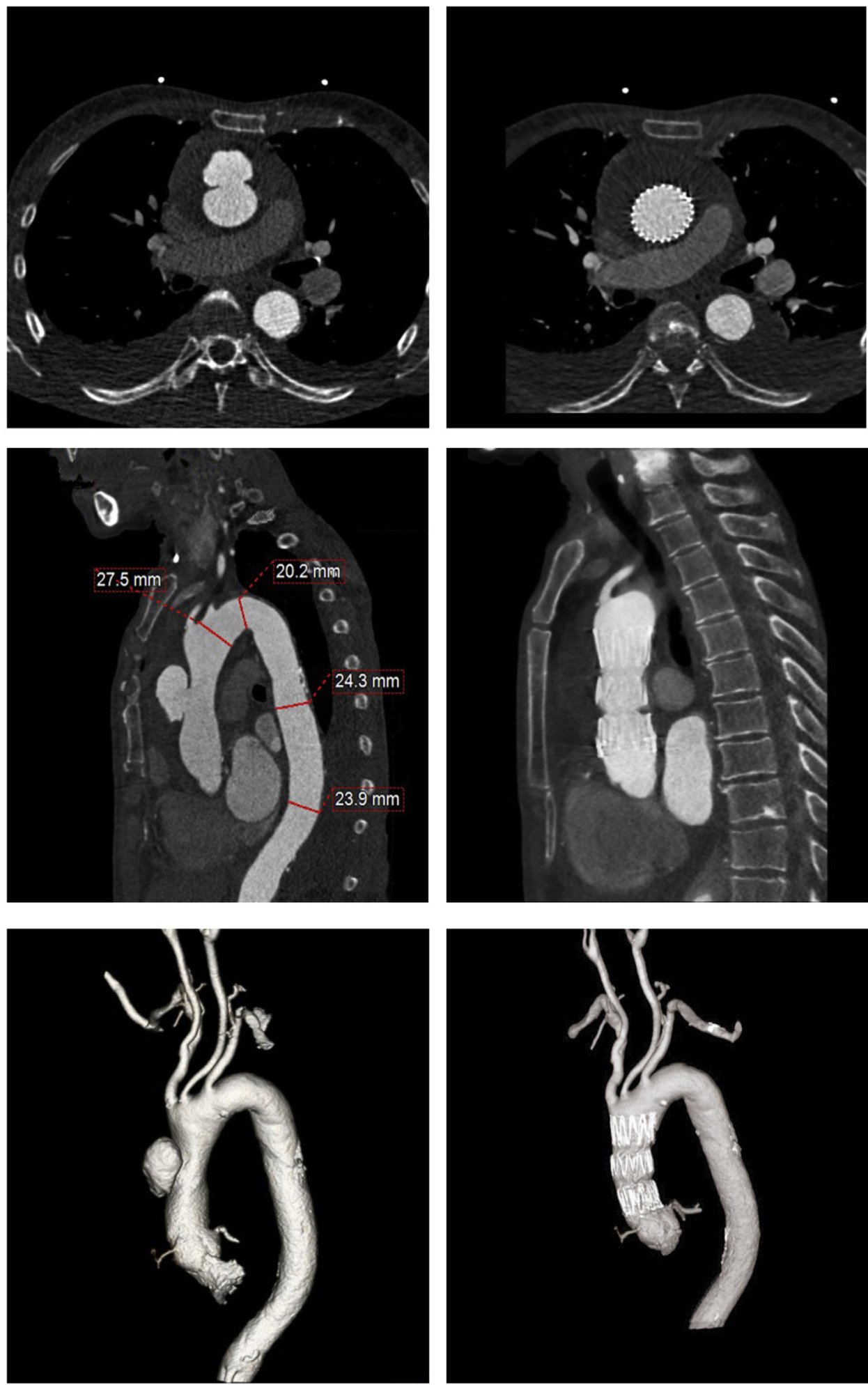

FIGURE 3. From top to bottom: 2-dimensional transverse and coronal sections of a proximal (type A) aortic dissection before (left) and after stent-grafting $(r i g h t)$, demonstrating thoracic endovascular aortic repair reconstruction and remodeling of the aorta. The bottom panels demonstrate the successful intervention in 3-dimensional reconstruction. 
TABLE 2. Current literature (mostly single or small case series) on proximal endovascular procedures over more than 10 years

\begin{tabular}{|c|c|c|c|c|c|c|c|c|c|c|}
\hline Author & Year & $\mathbf{n}$ & $\begin{array}{l}\text { Acute, } \\
\text { n (\%) }\end{array}$ & Stent-graft & $\begin{array}{l}\text { Access } \\
\text { route }\end{array}$ & $\begin{array}{c}\text { Follow-up, } \\
\text { mo } \\
\end{array}$ & $\begin{array}{c}\text { Early } \\
\text { mortality, } \\
\text { n }(\%) \\
\end{array}$ & Cause of death & Complications & Re-intervention \\
\hline Dorros et al & 2000 & 1 & $1(100)$ & Lecteba & $\begin{array}{c}\text { RFV Trans- } \\
\text { septal }\end{array}$ & 1 & $1(100)$ & Cardiac arrest & - & - \\
\hline Wang et $\mathrm{al}^{23}$ & 2003 & 1 & $1(100)$ & $\begin{array}{r}\text { Covered } \\
\text { Z-stent }\end{array}$ & Aorta & 12 & 0 & - & - & - \\
\hline Ihnken et $\mathrm{al}^{22}$ & 2004 & 1 & $1(100)$ & Gore & - & None & 0 & - & - & - \\
\hline Zhang et $\mathrm{al}^{24}$ & 2004 & 1 & 0 & $\begin{array}{r}\text { Gianturco } \\
\text { Z-stent }\end{array}$ & $\mathrm{TF}$ & 21 & 0 & - & $\begin{array}{l}\text { Aortic } \\
\text { regurgitation }\end{array}$ & Open surgery \\
\hline Zimpfer et $\mathrm{al}^{25}$ & 2006 & 1 & $1(100)$ & Jotec & $\mathrm{TF}$ & 1 & 0 & - & - & - \\
\hline Senay et al & 2007 & 1 & $1(100)$ & Medtronic & $\mathrm{TF}$ & None & 0 & - & Endoleak & - \\
\hline Palma et al & 2007 & 1 & 0 & Braile Biomed & $\mathrm{TF}$ & None & $1(100)$ & $\begin{array}{l}\text { Cardiac arrest } \\
\text { stent migration }\end{array}$ & - & - \\
\hline Ye et $\mathrm{al}^{30}$ & 2011 & 10 & $6(60)$ & Various & $2 \mathrm{LCCA}, 8 \mathrm{TF}$ & 35.5 & $1(10)$ & $\begin{array}{c}\text { Gastrointestinal } \\
\text { bleeding }\end{array}$ & - & $\begin{array}{l}\text { Balloon dilatation } \\
\text { for endoleak }\end{array}$ \\
\hline Metcalfe et $\mathrm{al}^{31}$ & 2012 & 1 & $1(100)$ & Medtronic & $\mathrm{TF}$ & None & 0 & - & - & - \\
\hline Gustavo et al & 2012 & 1 & $1(100)$ & Cook & Aorta & 32 & 0 & - & Tachycardia & - \\
\hline Ronchey et $\mathrm{al}^{33}$ & 2013 & 4 & $4(100)$ & Cook & $\mathrm{TF}$ & $15(4-39)$ & 0 & - & - & - \\
\hline Bahaeddin et al & 2013 & 1 & 0 & Cook & TA & 1 & 0 & - & $\begin{array}{l}\text { Aortic } \\
\text { regurgitation }\end{array}$ & - \\
\hline Eric et al & 2013 & 1 & $1(100)$ & Cook & TA & None & 0 & - & - & - \\
\hline Kölbel et al & 2013 & 1 & $1(100)$ & Cook & TA & 6 & 0 & - & - & - \\
\hline Frederic et al & 2013 & 1 & $1(100)$ & Jotec & TA & None & 0 & - & - & - \\
\hline Lu et al & 2013 & 15 & $5(33)$ & Cook & - & $22(12-31)$ & 0 & - & Arrhythmia & $\begin{array}{c}\text { Angioplasty and } \\
\text { stenting of left } \\
\text { renal artery }\end{array}$ \\
\hline Yuuya et al & 2014 & 1 & $1(100)$ & Gore & RCA & None & 0 & - & - & - \\
\hline Kimberly et al & 2014 & 1 & $1(100)$ & Medtronic & $\mathrm{TF}$ & None & 0 & - & - & - \\
\hline $\begin{array}{l}\text { Vallabhajosyula } \\
\text { et al }\end{array}$ & 2015 & 6 & $3(50)$ & $\begin{array}{l}\text { Cook } \\
\text { Amplatzer }\end{array}$ & $\begin{array}{r}4 \mathrm{TA}, 1 \mathrm{TF}, \\
1 \mathrm{LCCA}\end{array}$ & $33(3-57)$ & 0 & - & Endoleak Stroke & $\begin{array}{c}\text { Re-stenting for } \\
\text { endoleak }\end{array}$ \\
\hline Roselli et al & 2015 & 18 & $9(50)$ & $\begin{array}{r}\text { Cook, Gore, } \\
\text { Medtronic }\end{array}$ & $\begin{array}{c}5 \mathrm{TA}, 4 \mathrm{TAx} \\
9 \mathrm{TF}\end{array}$ & 12 median & 3 (17) & $\begin{array}{l}\text { Coronary } \\
\text { obstruction, } \\
\text { aortic rupture, } \\
\text { tamponade }\end{array}$ & $\begin{array}{l}\text { Contained aortic } \\
\text { rupture, endoleak, } \\
\text { stent migration, } \\
\text { apical PA }\end{array}$ & $\begin{array}{r}\text { Stent extension, } \\
\text { open surgery }\end{array}$ \\
\hline
\end{tabular}

$R F$, Right femoral vein; $T F$, transfemoral; $L C C A$, left common carotid artery; $T A$, transapical; $R C A$, right carotid artery; $T A x$, transaxillary; $P A$, pseudoaneurysm.

effects on the aortic valve function, or hypertension in this observational study. Our sample size is relatively small, but it represents one of the biggest case-series in the field and supports the feasibility of TEVAR in practical terms. We have no control group (medically treated or surgery) for comparison, but historical data suggests that surgery confers $25 \%$ perioperative mortality, and medical treatment is associated with $60 \%$ mortality. ${ }^{13,15,27,28}$ A propensitymatched comparison prior to any randomized study would probably be the next step to strengthen the data on TEVAR in the proximal aorta; current technology is unlikely to allow a broader application yet.

\section{CONCLUSIONS}

TEVAR is feasible and reveals promising early results in selected patients with proximal (type A) aortic dissection who are poor candidates for surgical repair. The current iteration of stent-graft technology however needs to be adapted to the specific features of the ascending aorta before TEVAR as a concept emerges for broader applications in the proximal aorta.

\section{Conflict of Interest Statement}

Authors have nothing to disclose with regard to commercial support.

\section{References}

1. Suenaga E, Sato M, Fumoto H. Ascending aortic replacement for acute type A aortic dissection in octogenarians. Gen Thorac Cardiovasc Surg. 2016r;64: $138-43$.

2. Rylski B, Hoffmann I, Beyersdorf F, Suedkamp M, Siepe M, Nitsch B, et al. Acute aortic dissection type A: age-related management and outcomes reported in the German Registry for Acute Aortic Dissection Type A (GERAADA) of over 2000 patients. Ann Surg. 2014;259:598-604. 
3. Nienaber CA, Fattori R, Lund G, Dieckmann C, Wolf W, von Kodolitsch Y, et al. Nonsurgical reconstruction of thoracic aortic dissection by stent-graft placement. N Engl J Med. 1999;340:1539-45.

4. Dake MD, Kato N, Mitchell RS, Semba CP, Razavi MK, Shimono T, et al. Endovascular stent-graft placement for the treatment of acute aortic dissection. N Engl J Med. 1999:340:1546-52.

5. Resch TA, Delle M, Falkenberg M, Ivancev K, Konrad P, Larzon T, et al. Remodeling of the thoracic aorta after stent grafting of type B dissection: a Swedish multicenter study. J Cardiovasc Surg (Torino). 2006;47:503-8.

6. Eggebrecht $H$, Nienaber CA, Neuhauser M, Baumgart D, Kische S, Schmermund A, et al. Endovascular stent-graft placement in aortic dissection: a meta-analysis. Eur Heart J. 2006;27:489-98.

7. Fattori R, Nienaber CA, Rousseau H, Beregi JP, Heijmen R, Grabenwoger M, et al. Results of endovascular repair of the thoracic aorta with the Talent Thoracic stent graft: the Talent Thoracic Retrospective Registry. J Thorac Cardiovasc Surg. 2006;132:332-9.

8. Hassoun HT, Matsumura JS. The COOK TX2 thoracic stent graft: preliminary experience and trial design. Semin Vasc Surg. 2006;19:32-9.

9. Kwolek CJ, Fairman R. Update on thoracic aortic endovascular grafting using the medtronic talent device. Semin Vasc Surg. 2006;19:25-31.

10. Makaroun MS, Dillavou ED, Kee ST, Sicard G, Chaikof E, Bavaria J, et al. Endovascular treatment of thoracic aortic aneurysms: results of the phase II multicenter trial of the GORE TAG thoracic endoprosthesis. J Vasc Surg. 2005;41:1-9.

11. Szeto WY, McGarvey M, Pochettino A, Moser GW, Hoboken A, Cornelius K, et al. Results of a new surgical paradigm: endovascular repair for acute complicated type B aortic dissection. Ann Thorac Surg. 2008;86:87-93; discussion 93-4.

12. Santini F, Montalbano G, Casali G, Messina A, Iafrancesco M, Luciani GB, et al. Clinical presentation is the main predictor of in-hospital death for patients with acute type A aortic dissection admitted for surgical treatment: a 25 years experience. Int J Cardiol. 2007;115:305-11.

13. Centofanti P, Flocco R, Ceresa F, Attisani M, La Torre M, Weltert L, et al. Is surgery always mandatory for type A aortic dissection? Ann Thorac Surg. 2006;82:1658-63; discussion 64.

14. Akin I, Nienaber C. Established indications for invasive treatment of thoracic aortic aneurysm [in German]. Dtsch Med Wochenschr. 2015;140:1747-52.

15. Pape LA, Awais M, Woznicki EM, Suzuki T, Trimarchi S, Evangelista A, et al. Presentation, diagnosis, and outcomes of acute aortic dissection: 17-year trends from the International Registry of Acute Aortic Dissection. J Am Coll Cardiol. 2015;66:350-8.

16. Trimarchi S, Nienaber CA, Rampoldi V, Myrmel T, Suzuki T, Mehta RH, et al. Contemporary results of surgery in acute type A aortic dissection: The International Registry of Acute Aortic Dissection experience. J Thorac Cardiovasc Surg. 2005; 129:112-22.

17. Shah A, Coulon P, de Chaumaray T, Rosario R, Khanoyan P, Boukhris M, et al. Novel technique: staged hybrid surgical and endovascular treatment of acute Type A aortic dissections with aortic arch involvement. J Cardiovasc Surg (Torino). 2006; 47:497-502.

18. Diethrich EB, Ghazoul M, Wheatley GH, Alpern J, Rodriguez-Lopez J, Ramaiah V, et al. Surgical correction of ascending type a thoracic aortic dissection: simultaneous endoluminal exclusion of the arch and distal aorta. J Endovasc Ther. 2005;12:660-6.

19. Dobrilovic N, Elefteriades JA. Stenting the descending aorta during repair of type A dissection: technology looking for an application? J Thorac Cardiovasc Surg. 2006;131:777-8.

20. Moon MC, Greenberg RK, Morales JP, Martin Z, Lu Q, Dowdall JF, et al. Computed tomography-based anatomic characterization of proximal aortic dissection with consideration for endovascular candidacy. J Vasc Surg. 2011;53:942-9.
21. Sobocinski J, O’Brien N, Maurel B, Bartoli M, Goueffic Y, Sassard T, et al Endovascular approaches to acute aortic type A dissection: a CT-based feasibility study. Eur J Vasc Endovasc Surg. 2011;42:442-7.

22. Ihnken K, Sze D, Dake MD, Fleischmann D, Van der Starre P, Robbins R Successful treatment of a Stanford type A dissection by percutaneous placement of a covered stent graft in the ascending aorta. J Thorac Cardiovasc Surg. 2004; 127:1808-10.

23. Wang ZG, Massimo CG, Li M, Pan SL, Zhang HK, Jing W, et al. Deployment of endograft in the ascending aorta to reverse type A aortic dissection. Asian J Surg. 2003:26:117-9.

24. Zhang H, Li M, Jin W, Wang Z. Endoluminal and surgical treatment for the management of Stanford Type A aortic dissection. Eur J Cardiothorac Surg. 2004:26:857-9.

25. Zimpfer D, Czerny M, Kettenbach J, Schoder M, Wolner E, Lammer J, et al Treatment of acute type a dissection by percutaneous endovascular stent-graft placement. Ann Thorac Surg. 2006;82:747-9.

26. Koschyk DH, Nienaber CA, Knap M, Hofmann T, Kodolitsch YV, Skriabina V, et al. How to guide stent-graft implantation in type B aortic dissection? Comparison of angiography, transesophageal echocardiography, and intravascular ultrasound. Circulation. 2005;112(9 suppl):I260-4.

27. Rampoldi V, Trimarchi S, Eagle KA, Nienaber CA, Oh JK, Bossone E, et al Simple risk models to predict surgical mortality in acute type A aortic dissection: the International Registry of Acute Aortic Dissection score. Ann Thorac Surg. 2007;83:55-61.

28. Tsai TT, Evangelista A, Nienaber CA, Trimarchi S, Sechtem U, Fattori R, et al Long-term survival in patients presenting with type A acute aortic dissection: insights from the International Registry of Acute Aortic Dissection (IRAD) Circulation. 2006;114(1 suppl):I350-6.

29. Ueda T, Fleischmann D, Dake MD, Rubin GD, Sze DY. Incomplete endograft apposition to the aortic arch: bird-beak configuration increases risk of endoleak formation after thoracic endovascular aortic repair. Radiology. 2010;255:645-52.

30. Ye C, Chang G, Li S, Hu Z, Yao C, Chen W, et al. Endovascular stent-graft treatment for Stanford type A aortic dissection. Eur J Vasc Endovasc Surg. 2011;42:787-94.

31. Metcalfe MJ, Karthikesalingam A, Black SA, Loftus IM, Morgan R, Thompson MM. The first endovascular repair of an acute type A dissection using an endograft designed for the ascending aorta. J Vasc Surg. 2012;55:220-2.

32. Lu Q, Feng J, Zhou J, Zhao Z, Bao J, Feng R, et al. Endovascular repair of ascending aortic dissection: a novel treatment option for patients judged unfit for direct surgical repair. J Am Coll Cardiol. 2013;61:1917-24.

33. Ronchey S, Serrao E, Alberti V, Fazzini S, Trimarchi S, Tolenaar JL, et al Endovascular stenting of the ascending aorta for type A aortic dissections in patients at high risk for open surgery. Eur J Vasc Endovasc Surg. 2013;45: 475-80.

34. Bossone E, Evangelista A, Isselbacher E, Trimarchi S, Hutchison S, Gilon D, et al. Prognostic role of transesophageal echocardiography in acute type A aortic dissection. Am Heart J. 2007;153:1013-20.

35. Comas GM, Leshnower BG, Halkos ME, Thourani VH, Puskas JD, Guyton RA, et al. Acute type a dissection: impact of antegrade cerebral perfusion under moderate hypothermia. Ann Thorac Surg. 2013;96:2135-41.

Key Words: type A aortic dissection, TEVAR, stent-graft, endovascular scaffold, 3D reconstruction, aortic repair 